\title{
Inventory Management Systems used by Manufacturing Small Medium and Micro Enterprises in Cape Town
}

\author{
Nikita Ngubane \\ Siphokazi Mayekiso \\ Sphelele Sikota \\ Siyanda Fitshane \\ Mamorena Matsoso \\ Juan-Pierré Bruwer* \\ Faculty of Business, Cape Peninsula University of Technology, P.O. Box 625, Cape Town, 8000, South Africa \\ Email: BruwerJP@cput.ac.za
}

\section{Doi:10.5901/mjss.2015.v6n1p382}

\section{Abstract}

Inventory management is regarded as one of the most important influencers of competitiveness, and is also seen as a key operational performance measure for Small Medium and Micro Enterprises (SMMEs) in inventory-intensive industries. Prior research shows that manufacturing SMMEs are confronted with increased competition from businesses that purchase and sell 'cheaper' manufactured products from countries such as China and India, among other; resulting in these manufacturing SMMEs to consequently struggle to develop. As such, it is imperative that SMMEs formalise their internal structures and systems in order to become more competitive. Moreover approximately $80 \%$ of SMMEs are believed to fail within their first 4 years of existence. Stemming from the latter the authors formulated the perception that SMMEs' overall existence is adversely influenced as a result of ineffectively managing its inventory, which evidently affects operations, production, customer relations and profitability, among other areas. The main objective of this study was to ascertain the how effectively inventory was managed by SMMEs, specifically in the manufacturing industry; situated in Cape Town. The study was descriptive in nature and was conducted using quantitative research methods. Data were collected by means of questionnaires from 21 SMMEs leaders in the manufacturing industry in the northern suburbs of Cape Town. It was found that although majority of respondents were aware of formal inventory management systems, they did not extensively make use of them. Ironically the inventory management systems which were used by respondents, though informal to a large extent, were found to be working for them.

Keywords: Inventory management systems, Small medium and micro enterprises, SMMEs, manufacturing

\section{Introduction}

Small Medium and Micro Enterprises (often referred to as SMMEs) are defined by the National Small Business Act No.102 of 1996 of South Africa as separate and distinct business entities, including co-operative enterprises and nongovernmental organisations, managed by one owner or more which, including its branches or subsidiaries, if any, are predominantly carried on in any sector or subsector of the economy (South Africa, 1996). Berry, et al. (2002) express the view that SMMEs have been actively promoted, by the South African government since before 1995 and, by Law, have been given the main responsibilities of enhancing economic growth, reducing unemployment and alleviating poverty. The latter is confirmed by the research conducted by Kesper (2001) which states that SMMEs are deemed to be at the forefront of economic development and are actively involved in the resolution of socio-economic problems. Albeit the afore-mentioned, it is believed that South African SMMEs are not achieving their legally imposed objectives as they should.

In the early 2000 Van Eeden, et al (2003) established that SMMEs, in general, had an overall failure-rate of between $70 \%$ and $80 \%$ over the course of 3 to 4 years. In more recent times, on average, approximately $80 \%$ of South African SMMEs are believed to fail within their first year of existence alone (Masama, et al., 2012). Masama, et al. (2012) imply that probable reasons for the high SMME failure rate is due to inadequate business skill development and training; 
lack of financial support, unstable business environments as well as inadequate business management. Particularly, the management of inventory is also a critical element that should be taken into account for business in inventory-intensive arenas (Terblanche, et al., 2013)

Curtis (1991) avers that inventory is an idle resource at best, and a liability at worst due to the sensitivity that lies in adopting the 'perfect' inventory management strategy. Koumanakos (2008) makes mention that, more often than not, excessive inventory is an indication of sloppy and inefficient management (broad), poor forecasting, haphazard scheduling, and inadequate attention to detail given to process and procedures. Koumanakos (2008) further adds that excess inventory can lead to: 1) having the wrong type of inventory on hand, 2) having the inferior inventory quantity on hand, 3) having the right inventory on hand but at the wrong location, and/or 4) having the right inventory on hand too early and/or too late. On the other hand, too little inventory often disrupts manufacturing operations, and increases the likelihood of poor customer service (Lwiki, et al., 2013).

Stemming from the above, it is clear that inventory can be regarded as both an asset and a liability for any business. In the statement of financial position, inventory is shown as a current asset and is generally utilised (i.e. bought and sold) to generate a steady stream of income for a business but if ineffectively managed, inventory can become a current liability (i.e. by not 'moving') in the form of potential cash (that is tied up) that cannot be converted. Notwithstanding the above Pillai (2010) is of the opinion that inventory management is a key driver in the stimulation of businesses development - particularly by becoming more competitive, as well as attaining operational performance in relation to the effective 'movement' of inventory.

Taking the above into account it is clear that inventory management is of paramount importance. In core if inventory is managed effectively, it can help a business become more profitable - decreasing expenditure (e.g. cost of sales, storage costs, shipping fees, etc.) and/or increasing income (e.g. sales, interest income, etc.). In the same vein, South African SMMEs do not have a sound 'track record' when it comes to their existence; resulting in them not attaining their legally imposed objectives to a great extent. As a result the authors formulated the perception that the existence rate of South African SMMEs is adversely influenced by the ineffective inventory management initiatives.

\section{Problem Statement}

Stemming from the above, the authors formulated the perception that South African SMMEs do not have a sound existence-rate due to ineffective inventory management initiatives.

\subsection{Research questions}

In order to provide insight on the identified research problem, the following research questions were asked:

- What are SMME leaders' perceptions regarding inventory management?

- What inventory management initiatives to SMME leaders make use of?

- How effective are these inventory management initiatives in SMMEs?

\section{Literature Review}

\subsection{An overview of South African SMMEs}

During the course of 1995 the South African government developed a national strategy for the development of small businesses; one year later, the National Small Business Act No.102 of 1996 was formally signed into Law (Kongolo, 2010). In this Act SMMEs are defined as separate and distinct business entities, including co-operative enterprises and non-governmental organisations, managed by one owner or more which, including its branches or subsidiaries, if any, are predominantly carried on in any sector or subsector of the economy (South Africa, 1996). Furthermore the latter definition groups SMMEs in relation to size based on three criteria: 1) the number of employees they employ, 2) the total annual turnover made, and 3) their estimated gross asset value (excluding fixed property). For the sake of clarity the criteria for manufacturing SMMEs are collaborated in Table 1 below: 
Table 1: The categorisation of Manufacturing SMME sizes (Source: South Africa, 1996)

\begin{tabular}{|l|l|l|l|}
\hline Enterprise Size & Number of employees & Total annual turnover & $\begin{array}{l}\text { Total gross asset value } \\
\text { (excluding fixed property) }\end{array}$ \\
\hline Medium & Between 51 and 200 & Between R10 000 001 and R40 000 000 & Between R3 750 001 and R15000 000 \\
\hline Small & Between 21 and 50 & Between R4 000001 and R10 000 000 & Between R1500 001 and R3 750 000 \\
\hline Very small & Between 6 and 20 & Between R150 001 and R4 000 000 & Between R100 001 and R1 500 000 \\
\hline Micro & Between 0 and 5 & Between R0 and R150 000 & Between R0 and R100 000 \\
\hline
\end{tabular}

In the latter Act, the main objective imposed on South African SMMEs is to spur economic growth; mainly through means of creating jobs and alleviating poverty. To put the latter in perspective Ngary, et al. (2014) aver that South African SMMEs are responsible for absorbing approximately $80 \%$ of the national labour force while Swart (2011) adds that SMMEs are believed to contribution up to $30 \%$ to the national Gross Domestic Product (GDP). This view is substantiated by Kongolo (2010) who points to the fact that these entities account for $91 \%$ of all business entities operating in South Africa. Hence it is no surprise that SMMEs are regarded as major role players - as catalysts - in the development of any country (Shah \& Khedkar, 2006).

Albeit the above Siwangaza, et al. (2014) noted that South African SMMEs do not have a good 'track record' when it comes to remaining going concern enterprises. In the early 2000's Van Eeden et al. (2003) found that between 70\% and $80 \%$ of South African SMMEs failed within their first 3 years of existence. During the course of 2010 approximately $80 \%$ of these entities were reported to fail after operating for a maximum of 5 years (Bruwer \& Watkins, 2010) translating to approximately 10000 business entities failing on a monthly basis (Biyase, 2009). In more recent times however $75 \%$ of South African SMMEs have had to close the doors after operating for an average of 42 months (Ngari, et al., 2014; Fatoki, 2012).

\subsection{Factors influencing South African SMME failure}

According to Fatoki (2012) the South African SMME failure rate is one of the highest in the world. In essence the astronomical failure rate of these entities is generally blamed on economic factors (Salie, et al., 2014):

- Macro economic factors: These factors are variables which stem from outside an organisation; beyond the control of a business' management.

- Micro economic factors: These factors are variables which stem from within an organisation which are controllable, to a large extent, by a business' management.

Based on research conducted by Terziovski (2010) and Abor and Quartey (2010) it was found that inadequate strategic planning processes, the lack of performance measurement systems, limited access to appropriate technologies; limited access to non-financial resources, lack of management skills and training limited access to markets, excessive government laws, among other economic factors, adversely influenced South African SMMEs' business continuation statistics. In particular the element of competition was also found to be an impeding economic factor for manufacturing SMMEs to achieve their full potential in terms of development. The latter is especially the case since products can be manufactured (and imported) at a much 'cheaper' rate from countries such as China and India. This dispensation makes it extremely difficult for South African manufacturing SMMEs to develop appropriate strategies to become 'worthy' competitors (Singh, 2010).

Notwithstanding the above it is of paramount importance that South African SMMEs, particularly those entities based in the manufacturing industry, need to formalise (enhance) their internal structures and systems in order to become more competitive and efficient in the process (Terziovski, 2010). Holistically speaking the latter greatly constitutes optimising both profitability (maximising income and minimising expenditure) and liquidity (maximising 'cash on hand' situations) (Bruwer, 2010). For inventory-intensive SMMEs, a vital system which should be considered for enhancement is its inventory management system. 


\subsection{An introduction to inventory management and inventory systems}

Inventory management includes developing, implementing, and administering inventory procedures, policies and systems (Cox, et al., 1991). According to Flynn, et al. (2005) the two most common approaches to inventory management entail: 1) the periodic inventory system, and 2) the perpetual inventory system. Thought the physical handling of inventory does not differ in these two inventory systems, the recording of inventory in the books of a business differs greatly from one system to the next.

- Periodic inventory system: Records pertaining to inventory are updated at the end of a financial year (a 12 month period) by making use of stock counts. There is no on-going record of inventory maintained through this system.

- Perpetual inventory system: Records pertaining to inventory are updated as soon as there is a movement in inventory (i.e. purchases and/or sales). There is an on-going record of inventory maintained through this system.

These two inventory systems enable management of a business to make important business decisions pertaining to inventory-related matters. In core depending on the inventory system that a business adopts, it will have a major influence on how inventory is actually managed.

\subsection{Inventory management systems}

As previously mentioned inventory management is important as it can either 'make or break' a business from a profitability and/or liquidity point of view (Flynn, et al., 2005). Large organisations are reported to make use of inventory management practices not only as a tool, but rather as a type of strategy to improve overall efficiency to become 'worthy' competitors in international markets (Imeokparia, 2013; Harringtion, et al., 1990).

When emphasis is placed on South African SMMEs, it is clear that they do not necessarily possess the relevant resources (Ngary, et al., 2014) to make use of formal inventory management systems like their larger counterparts. These limitations include a lack of initiative, a lack of expertise as well as financial limitations (Narayanapillai, 2010). In fundamental nature the management of inventory is an essential task for SMME management to optimise profitability and/or liquidity; for this reason it is important to place focus on recognised 'tools' for forecasting, replenishing and overall handling of inventory. Among these 'tools' the four most popular and widely-used are the following:

- Economic Order Quantity (EOQ): This tool is used to determine the best time to order the most economic quantity of inventory. This is generally done by 'assuming' that there is a fixed ordering cost, the demand of inventory will remain constant, there is no discount available on the purchases of inventory and only one product is ordered (Le Roux \& Lotter, 2003).

- Activity Based Costing (ABC): This tool takes into account that certain activities (in a manufacturing setup) cause costs and that products are created by means of these activities. In core, relevant resources are allocated to all products and/or services in relation to the overall consumption by each activity (Niemand, et al. 2007)

- Just In Time (JIT): This tool ensures that inventory is received shortly before it is used - hence the term 'just in time'. This approach assists a business to hold a minimum amount if inventory at a given time and obtain the greatest optimum mix of current assets - the best balance between actual cash on hand and potential cash on hand (e.g. debtors and inventory) (Niemand, et al. 2007).

- Enterprise Resource Planning (ERP): This tool is electronic in nature and assists with the precise allocation of resources (e.g. inventory) to the most appropriate activities in a business, in the shortest amount of time at the lowest possible cost (SAP, 2011).

An effective inventory management system will enable any organisation to minimise its costs pertaining to inventory (i.e. purchasing, storage, transport, etc.) however as market conditions are not predictable to a large extent, there may be chances that inventory shortages may occur (Pillai, 2010). In general, inventory management systems should cause more good than harm.

\section{Research Design and Methodology}

According to Collis and Hussey (2009) the research design of any research study can be categorised by means of its purpose, process, logic and outcome. The research design for this study took the following approach: 
- Purpose: This study was descriptive in nature as the main intention of this study was to describe a certain phenomenon at hand.

- Process: This study was quantitative research and fell within the ambit of the positivistic research paradigm. In essence, quantitative data were gleaned from respondents through means of a questionnaire tool.

- Logic: This research was deductive in nature as the perception(s) of the authors derived from consulting existing literature, after which it was examined by means of empirical observations.

- Outcome: This study was regarded as basic research as the main intention of the authors was to shed light on a particular phenomenon at hand.

The research method deployed for this research study was that of survey research. In essence, a questionnairetool was used to collect data from a certain sample relating to a certain population. The main reason for choosing this methodology was to obtain data in such a manner that it could address the nature of the research questions (as covered in paragraph 2.1) better when compared to other data collection methodologies. Furthermore, time was of the essence for the authors as data had to be collected in a period of 3 weeks only.

The respondents were production managers and/or financial managers and/or supply chain managers and/or general managers of manufacturing SMMEs. The ultimate reason for choosing these respondents was that these people were directly involved in making decisions pertaining to inventory in their respective SMME(s).

The sampling method used was that of non-probability sampling, a mixture of purposive sampling and convenience sampling. In essence the actual size of the population was unknown while the main intention of the authors was to glean rich data to solve and/or mitigate the identified research problem.

In order for respondents' responses to be regarded as valid, they had to adhere to the following delineation criteria:

- Respondents should have been production managers and/or financial managers and/or supply chain managers and/or general managers in a SMME.

- These SMMEs should have been operating in the manufacturing industry.

- These SMMEs should have been operating in the northern suburbs; Cape Town.

- These SMMEs should have satisfied the definition of a small business as per the South African Small Business Act No. 102 of 1996.

- These SMMEs should have been in operation for at least 1 year.

- These SMMEs should have employed between 5 and 100 employees.

- In addition to the above, relevant ethical considerations were taken into account for this research study:

- Respondents were informed of the purpose of the research study.

- Respondents were informed that their participation in the research study is voluntary in nature.

- All respondents were informed that information supplied by them would purely be used for research purposes and their responses would be kept anonymous.

- All respondents were guaranteed that all information provided by them would be treated with the highest levels of confidentiality.

\subsection{Limitations of the study}

Time and money constraints were major limitations of the study. This research study was conducted with no formal budget and/or external funding and had to be conducted over a period of five months

\section{Data Analysis and Discussion of Findings}

\subsection{Respondent demographics}

A total of 50 questionnaires were distributed (by hand) to respondents. Of these 50 questionnaires, only 21 responses (42\% response rate) were received. All 21 of the received responses were valid. Respondents were asked a variety of questions in an attempt to examine whether they adhered to the strict delineation criteria as mentioned above:

- A total of $100 \%$ of respondents operated in the manufacturing industry.

- Respondents indicated that $19.05 \%$ were owner-managers while $61.9 \%$ of respondents were general managers. The remaining $19.05 \%$ of respondents were either production managers, financial managers or supply chain managers.

- On average respondents had been in their respective positions for 3.19 years. 
Additionally respondents were asked to indicate how long their respective business has been in operation. The findings made are shown in Table 2 below:

Table 2: Duration (in years) of respondents' business in operation

\begin{tabular}{|c|c|}
\hline Statistic & Year \\
\hline Maximum & 5 years \\
\hline Minimum & 1 year \\
\hline Average & 2.71 years \\
\hline
\end{tabular}

Furthermore respondents were asked to indicate the number of full time employees that they employed. This was done to ascertain the actual size of the manufacturing SMME with which the respondent was associated. A total of $76 \%$ of respondents operated in micro, very small and small manufacturing businesses (employed between 0 and 50 employees) while $24 \%$ of respondents operated in medium manufacturing businesses (employed between 51 and 200 employees).

To obtain a better understanding of how the formal business education of respondents they were asked to indicate the highest qualification(s) they possess. The following dispensation emerged in Table 3.

Table 3: Highest qualification of respondents

\begin{tabular}{|l|c|}
\hline Qualification type & Percentage of respondents \\
\hline Grade 12 & $9.52 \%$ \\
\hline Certificate/Diploma/Degree & $66.70 \%$ \\
\hline Postgraduate qualification & $14.30 \%$ \\
\hline No qualification & $9.52 \%$ \\
\hline
\end{tabular}

From the above it is evident that respondents, on average, were general managers in medium manufacturing businesses that have been in operation for close to 3 years. In addition, the average respondent had at least a certificate and/or diploma and/or degree.

\subsection{The perception of respondents on inventory management}

Respondents were asked to rate a certain statement by means of using a four point likert scale with options for $1=$ 'Strongly Agree', 2= 'Agree', 3= 'Disagree', 4= 'Strongly Disagree'. The statement that was given to respondents for rating read: "In my business, inventory management has the primary objectives to improve customer service, allow for smooth business operations and keeping inventory costs at a minimum. The responses received are shown in Table 4 below:

Table 4: Rating of the statement pertaining to the main objectives of inventory management

\begin{tabular}{|l|c|}
\hline Response & Importance of Inventory management \\
\hline Strongly Agree & $67 \%$ \\
\hline Agree & $29 \%$ \\
\hline Strongly Disagree & $5 \%$ \\
\hline Disagree & $0 \%$ \\
\hline
\end{tabular}

From the table above it is evident that majority of respondents (95\%) were in agreement with the statement pertaining to the main objectives of inventory management (as it is described in literature). To substantiate whether respondents were in agreement as to what "inventory" is they were then asked, in a similar fashion, to rate the statement: "I regard inventory as the value and/or quantity of raw materials, supplies, work in progress stock, stock in transit and/or finished goods" A total of $86 \%$ of respondents responded favourably to this statement.

\subsection{The perception of the big four inventory management systems}

Respondents were asked to rate the following statement on a four point likert scale with options for 1= 'Strongly Agree', 2= 'Agree', 3= 'Disagree', 4= 'Strongly Disagree': "The following inventory management system(s) is of a great advantage 
to my business / will be to a great advantage in my business". The responses received are collaborated in Table 5 below:

Table 5: Perception of advantages of the big four inventory management systems

\begin{tabular}{|l|c|c|c|c|}
\hline Response & ERP & JIT & ABC & EOQ \\
\hline Strongly Agree & $29 \%$ & $38 \%$ & $48 \%$ & $29 \%$ \\
\hline Agree & $33 \%$ & $43 \%$ & $24 \%$ & $52 \%$ \\
\hline Strongly Disagree & $19 \%$ & $19 \%$ & $19 \%$ & $10 \%$ \\
\hline Disagree & $14 \%$ & $0 \%$ & $5 \%$ & $0 \%$ \\
\hline No response & $5 \%$ & $0 \%$ & $5 \%$ & $10 \%$ \\
\hline
\end{tabular}

From the table above it is clear that, in majority of cases, and based on the perception of respondents, the implementation of the big four inventory management systems will be advantageous to manufacturing SMMEs. The inventory management systems shown to be advantageous (by means of perception only) were that of EOQ (81\% positive perception), JIT (81\% positive perception), ABC (72\% positive perception), and ERP (62\% positive perception).

\subsection{Factors influencing inventory management strategy (broad)}

According to popular literature, there are many factors which influence SMMEs' decision of implementing certain inventory management strategy. As such respondents were asked to indicate which factors influenced their overall decision to make use of their current inventory management strategy(s). Again respondents were asked to rate a statement on a four point likert scale with options for 1= 'Strongly Agree', 2= 'Agree', 3= 'Disagree', 4= 'Strongly Disagree': "The following factors influenced my decision to adopt my current inventory management strategy". The responses received are collaborated in Table 6 below:

Table 6: Factors influencing the inventory management strategies of respondents

\begin{tabular}{|l|c|c|c|c|}
\hline Factor & Strongly agree & Agree & Disagree & Strongly disagree \\
\hline Difficulty to convert inventory to cash & $10 \%$ & $67 \%$ & $19 \%$ & $5 \%$ \\
\hline Effectiveness of business systems & $38 \%$ & $57 \%$ & $5 \%$ & $0 \%$ \\
\hline Limited resources on hand & $38 \%$ & $57 \%$ & $5 \%$ & $0 \%$ \\
\hline Mismanagement of inventory & $57 \%$ & $38 \%$ & $5 \%$ & $0 \%$ \\
\hline Overstocking of inventory & $48 \%$ & $43 \%$ & $10 \%$ & $0 \%$ \\
\hline Supplier delivery reliability & $14 \%$ & $14 \%$ & $57 \%$ & $14 \%$ \\
\hline Supply chain competitiveness & $43 \%$ & $48 \%$ & $10 \%$ & $0 \%$ \\
\hline
\end{tabular}

From the table above it is interesting to note that the factors which influenced the decision of respondents to adopt a certain management strategy(s) most were that of:

- Effectiveness of business systems: Influenced respondents $95 \%$ of the time.

- Limited resources on hand: Influenced respondents $95 \%$ of the time.

- Mismanagement of inventory: Influenced respondents $95 \%$ of the time.

- Overstocking of inventory: Influenced respondents $91 \%$ of the time.

- Supply chain competitiveness: Influenced respondents $91 \%$ of the time.

- Difficulty to convert inventory to cash: Influenced respondents $77 \%$ of the time.

What was also pertinent is that the reliability of suppliers to deliver played no role in the decision to adopt certain management strategy(s) $71 \%$ of the time.

\subsection{Inventory management strategy(s) deployed by respondents}

In order to determine what inventory management strategy respondents deployed in their respective businesses, they were asked two questions, in the form of a 2 point likert scale with options for 1= 'Yes', 2= 'No'.

Firstly respondents were asked to rate the statement which reads: "I make use of the following inventory system(s) in my business". A total of $19.05 \%$ of respondents indicated that they made use of the periodic inventory system, while $38.1 \%$ of respondents indicated that they made use of the perpetual inventory system. Respondents who indicated that 
they do not make use of any of the latter inventory systems (42.9\%) mentioned that they made use of informal inventory systems/customised inventory systems.

Lastly, respondents had to rate the following statement: "In my business I make use of the following inventory management systems". The following dispensation emerged in Table 7.

Table 7: Inventory management systems used by respondents

\begin{tabular}{|c|c|}
\hline Inventory management system & Favourable answer (percent) \\
\hline ABC & $14 \%$ \\
\hline EOQ & $14 \%$ \\
\hline JIT & $52 \%$ \\
\hline ERP & $14 \%$ \\
\hline
\end{tabular}

From the table above it is clear that majority of respondents, only by a fraction, actively make use of JIT, while all other inventory management systems are largely neglected. It is important to note that respondents who indicated that they made use of the latter inventory management systems were mostly medium enterprises.

\section{Conclusion}

From the above it is clear that respondents knew what inventory, inventory systems and inventory management were about. Although they are aware of the latter it was revealed that respondents do not make adequate use of formal inventory management systems available to them. Albeit the above, it is evident that respondents did in fact make use of more informal inventory management systems and also deployed customised inventory management strategies.

Taking the above into account, as well as the fact that respondents' manufacturing SMMEs were in operation for close the three years, it means that they must be doing something correct in the sense of inventory management as a whole. Unfortunately it cannot be guaranteed that the inventory management systems and inventory management strategies deployed by manufacturing SMMEs will not guarantee and enhancement of business operations, profitability and liquidity.

\section{References}

Abor, J. \& Quartey, P. 2010. Issues in SME Development in Ghana and South Africa. International Research Journal of Finance and Economics. 39(1): 218-228.

Berry, A., Cassim, R., Kesper, A., Rajaratnam, B., Van Seventer, D. \& Von Blottnitz, M. 2002. The Economics of SMME's in South Africa [Online]. Available from: http://www.tips.org.za/files/506.pdf [Accessed on 25/09/2014].

Biyase, L. 2009. DTI to look at how crisis hurts small enterprises. [Online] Available from: http://www.highbeam.com/doc/1G1198340345.html [Accessed on: 25/09/2014].

Bruwer, JP. 2010. Sustainability of South African FMCG SMME retail businesses in the Cape Peninsula. Dissertation submitted for the full requirements of a MTech: Internal Auditing. Cape Peninsula University of Technology. Cape Town.

Bruwer, J-P. \& Watkins, A. 2010. Sustainability of fast moving consumer goods retail SMMEs. African Journal of Business Management. 4(16): 3550-3555.

Collis, J. \& Hussey, R. 2009. Business Research: A practical guide for undergraduate and post graduate students. Hampshire: Palgrave Macmillan

Curtis T. 1991. A site inventory of the sandy coasts of Ireland. In: A guide to the sand dunes of Ireland. M.B. Quigley (Ed.). EUCC, Ireland.

Fatoki, O. 2012. An Investigation into the Financial Management Practices of New Micro-enterprises in South Africa. Journal of Social Science, 33(2): 179-188.

Cox, J., Hoy, F., Tate, C., Hoy, V. 1991. Small Business Management and Entrepreneurship. Boston, MA: PWS-Kent Publishing Company.

Flynn, D., Koornhof, C., Kleynhans, K., Meyer. L. \& Posthumus, L. 2005. Fundamental Accounting. Cape Town, Juta.

Harrington, T., Lambert, D. \& Vance, M. 1990. Implementing and Effective Inventory Management System. International Journal of Physical Distribution \& Logistics Management. 20(9): 17-23.

Imeokparia, L. 2013. Inventory Management System and Performance of Food and Beverages Companies in Nigeria. Joirnal of Mathematics. 6(1): 24-30.

Kesper, A. 2001. Making a living in the city - success and failure of small enterprises in the Johannesburg Inner City. Africa Insight,31(1): 50-58.

Kongolo, M. 2010. Job creation versus job shedding and the role of SMEs in economic development. African Journal of Business 
Management. 4(11): 2288-2295.

Koumanakos, P. 2008. The effect of inventory management on firm performance. International Journal of Productivity and Performance Management. 57(5):355-369.

Le Roux, G. \& Lotter, W. 2003. Basic principles of cost and management accounting. Cape Town, Juta.

Lwiki, T., Ojera, P., Mugend, N. \& Wachira, V. 2013. V. The impact of inventory management practices on Financial Performance of Sugar Manufacturing firms in Kenya. International Journal of Business, Humanities and Technology; 3(5): 75-85.

Masama, B., Ndlovu, E., Mambwe, T., Rabohome, C., Chakabva, O., Fologang, B., Badze, T. \& Bruwer J-P. 2012. Enterprise risk management: A managing 'partner' for business success. African Journal of Business Management. 6(48): 11782-11786.

Narayanapillai, R. 2010. An Evaluation of Inventory and performance in Indian machine tool SMEs: An exploratory study. International Journal of Innovation and Technology Management. 7(4): 216-225

Ngary, C., Smit, Y., Bruwer, J-P. \& Ukpere, W. 2014. Financial Performance Measures and Business Objectives Attainment in Fast Food SMMEs in the Cape Metropolis: A preliminary Liability and Suitability analysis. Mediterranean Journal of Social Sciences. $5(20)$ : 909-921.

Niemand, A., Meyer, L., Botes, V. \& Van Vuuren, S. 2007 Fundamentals of cost and management accounting. Cape Town, LexisNexis.

Pillai, R. 2010. Inventory management performance in machine tool SMEs: What factors do influence them? Journal of Industrial Engineering and Management. 3(3): $542-560$.

Salie, M., Strauss, N., Davids, M., Smit, Y., Boshoff, S. \& Bruwer, J-P. 2014. The effects of sin tax on the profitability of SMME convenience stores in the Cape Metropole. Topclass Journal of Business Management and Innovations. 1(2): 25-36.

SAP. 2011. SAP Education: Building the skills that build valued. Berlin, Privately Published.

Shah, T, \& Khedhkar, A. 2006. Case on successful SME financing - SIDBI Indian Institute of planning and Management (IIPM), Ahmedabad.

Singh, R., Garg, S. \& Deshmukh, S. 2010. The competitiveness of SMEs in a globalized economy: Observations from China and India. Management Research Review. 33(1): 54-65.

Siwangaza, L., Smit, Y., Bruwer, J-P. \& Ukpere, W. 2014. The Status of Internal Controls in Fast Moving Small Medium and Micro Consumer Goods Enterprises within the Cape Peninsula. Mediterranean Journal of Social Sciences. 5(10): 163-175.

South Africa. 1996. The Small Business Act No. 102 of 1996, Pretoria, Government Printer.

Terblanche, N., Beneke, J., Corbishley, K., Frazer, M., Pentz, C., Venter, P. \& Bruwer, J-P. 2013. Retail Management: A South African Perspective. Cape Town: Oxford University Press.

Terziovski, M. 2010. Innovation practice and its performance implications in small and medium enterprises (SMEs) in the manufacturing sector: a resource-based view. Strategic Management Journal. 31(8): 892-902.

Van Eeden, S., Viviers, S. \& Venter, D., 2003. A comparative Study of selected problems encountered by small businesses in the Nelson Mandela, Cape Town and Egoli metropoles. Management Dynamics. 12(3):13-23. 